\title{
Primer caso de ciguatera en el caribe colombiano por Seriola zonata (Mitchill, 1815) (Pisces: Carangidae)
}

\author{
Ricardo Alvarez
}

El registro del primer caso de ictiosarcotoxicosis de naturaleza indeterminada, aséptica no específica, mejor conocida como ciguatera, causada por la ingestión de la carne de un medregal quimeque (Seriola zonata) no deja duda sobre la presencia de dinoflagelados con propiedades tóxicas en las aguas adyacentes a los departamentos de Bolívar y Sucre en el Caribe colombiano. El medregal (macho, $4-5 \mathrm{~kg}, 400-$ $500 \mathrm{~mm}$ de longitud) fue capturado utilizando troleo durante un concurso de pesca deportiva organizada por el Club de Pesca de Cartagena frente a las costas de los departamentos citados en el Bajo Fríjol, aproximadamente a 12 millas de la isla Tortuga, el 5 de julio de 1994.

Este registro se basa en la información recopilada sobre la intoxicación sufrida por siete personas de dos familias vecinas de Cartagena, una de las cuales a través del padre de 44 años recibió como obsequio el medregal eviscerado, sin grasa ni gónadas, el mismo día que fue pescado y conservado. El pescado fue preparado en postas y frito, después de lo cual tanto los padres (44 y 39 años) como los tres hijos varones (11, 9 y 6 años) lo comieron en su totalidad compartiendo dos postas con una familia vecina, una señora de 45 años y su hija de 15 años.

Las personas intoxicadas comensaron a presentar los siguientes síntomas: cefalea, diarrea, vómito, hiporreflexia osteotendinosa, urticaria, conjuntivitis, dolor y disminición de la agudeza visual. Ante el cuadro clínico se les diseñaron diferentes tratamientos sintomáticos, pues, cada familia asistió a diferentes hospitales; se les administró dextrosa, lactato ringer, diuréticos, antineuríticos B1y B2, lavado estomacal y corticoides, así como alcohol para aliviar las molestias (dolores y urticarias) en las piernas. No hubo fallecimientos y en todos los casos se obtuvieron resultados positivos con mejora progresiva entre un día y una semana. Los más afectados fueron el hijo de 11 años (cefalea y disminución de la agudeza visual) y la señora de la familia vecina de 45 años (dolor y conjuntivitis del ojo derecho), pues, los síntomas se prolongaron durante una semana.

El padre de la primera familia y algunos de sus compañeros en las labores de mantenimiento y conducción de embarcaciones de pesca deportiva, afirman que estos casos de intoxicación por ingestión de pecado no son raros en el área de Cartagena y que, por lo menos, cinco especies pueden producirlas: barracudas (Sphyranea), cabrillas (Cephalopholis), chernas (Mycteroperca), dorados (Coryphaena), jureles (Caranx) y medregales (Seriola); dos tunas (Thunnus) y jureles (Caranx) que tienen carne negra, producen comúnmente urticaria $y$ dos sierras (Scomberomones) y bocachicos (Prochilodus) que tienen carne roja o rosada, pueden producir respuestas alérgicas.

Estos testimonios comprueban y respaldan los apuntes de Martínez (1-3) y los registros del primer caso (1) y segundo caso (4) de ictiotoxicosis ocacionada por la barracuda (Spyranea barracuda) en pobladores de Santa Marta (Magdalena) y de Cartagena (Bolívar), respectivamente, en el Caribe de Colombia. Es muy interesante el registro del bocachico (Prochilodus magdalenae) como causante de reacciones alérgicas, pues, por muchos años, ha sido la especie más importante de las pesquerías de la cuenca del Magdalena y muy apreciada por la calidad y sabor de su carne. 
El presente registro es el primer caso de ciguatera para la familia Carangidade y para el medregal quimeque (Seriola zonata) en las costas colombianas.

\section{Referencias}

1. Martínez A. Ictiosarcotoxicosis: una intoxicación potencialmente frecuente. Tribuna Médica 1977;56:3440.
2. Martínez A. Ictiosarcotoxicosis: una intoxicación potencialmente frecuente. Medicina UIS 1977;7(7):5594.

3. Martínez A. Ictiosarcotoxicosis en Colombia. Acta Méd Colomb 1984;9(1):22-7.

4. Alvarez-León R. Ictiotoxicosis ocasionada por Sphyranea barracuda (Walbaum) en el Caribe colombiano. Rev Acta Médica de Cartagena 1993;4(4):9 10 . 